https://helda.helsinki.fi

Older persons with signs of frailty in a home-based physical exercise intervention: baseline characteristics of an RCT

\title{
Suikkanen, Sara
}

$2019-10$

Suikkanen , S , Soukkio , P , Pitkälä , K, Kääriä , S , Kautiainen , H , Sipilä , S , Kukkonen-Harjula , K \& Hupli , M 2019 , ' Older persons with signs of frailty in a home-based physical exercise intervention: baseline characteristics of an RCT ' , Aging Clinical and Experimental Research, vol. 31 , no. 10 , pp. 1419-1427 . https://doi.org/10.1007/s40520-019-01180-z

http://hdl.handle.net/10138/308461

https://doi.org/10.1007/s40520-019-01180-z

cc_by

publishedVersion

Downloaded from Helda, University of Helsinki institutional repository.

This is an electronic reprint of the original article.

This reprint may differ from the original in pagination and typographic detail.

Please cite the original version. 


\title{
Older persons with signs of frailty in a home-based physical exercise intervention: baseline characteristics of an RCT
}

\author{
Sara Suikkanen ${ }^{1}$ (1) Paula Soukkio ${ }^{1} \cdot$ Kaisu Pitkälä ${ }^{2} \cdot$ Sanna Kääriä $^{3} \cdot$ Hannu Kautiainen ${ }^{2} \cdot$ Sarianna Sipilä $^{4}$. \\ Katriina Kukkonen-Harjula ${ }^{1} \cdot$ Markku Hupli $^{1}$
}

Received: 18 December 2018 / Accepted: 19 March 2019 / Published online: 2 April 2019

(c) Springer Nature Switzerland AG 2019

\begin{abstract}
Background Increasing the level of physical activity among persons with signs of frailty improves physical functioning. There is a lack of long-term supervised physical exercise intervention studies including a validated definition of frailty.

Aims To present baseline characteristics of persons with signs of frailty participating in a randomized long-term home-based physical exercise trial (HIPFRA), and to study associations between the severity of frailty, functional independence and health-related quality-of-life (HRQoL).

Methods Three hundred persons, $\geq 65$ years old and with signs of frailty (assessed by Fried's phenotype criteria) were recruited from South Karelia, Finland and randomized to a 12-month physiotherapist-supervised home-based physical exercise program $(n=150)$, and usual care $(n=150)$. Assessments at the participants' homes at baseline, and after 3, 6 and 12 months included the Short Physical Performance Battery (SPPB), the Functional Independence Measure (FIM), HRQoL (15D) and the Mini-Mental State Examination (MMSE).

Results Eligibility was screened among 520 persons; 300 met the inclusion criteria and were randomized. One person withdrew consent after randomization. A majority (75\%) were women, 182 were pre-frail and 117 frail. The mean age was 82.5 (SD 6.3) years, SPPB 6.2 (2.6), FIM 108.8 (10.6) and MMSE 24.4 (3.1) points, with no significant differences between the study groups. Inverse associations between the severity of frailty vs. FIM scores and HRQoL ( $p<0.001$ for both) were found. Conclusions Our participants showed marked physical frailty without major disabilities. The severity of frailty seems to be associated with impaired functional independence and HRQoL.
\end{abstract}

Trial registration: ClinicalTrials.gov NCT02305433

Keywords Frailty $\cdot$ Exercise $\cdot$ Disability $\cdot$ Health-related quality-of-life $\cdot$ Community-dwelling older people

Sara Suikkanen

sara.suikkanen@eksote.fi

1 Rehabilitation, South Karelia Social and Health Care District, Valto Käkelän katu 3, 53130 Lappeenranta, Finland

2 Department of General Practice, and Helsinki University Hospital, Unit of Primary Health Care, University of Helsinki, Tukholmankatu 8 B, 00290 Helsinki, Finland

3 Aureolis Oy, Hevosenkenkä 3, 02600 Espoo, Finland

4 Gerontology Research Center, Faculty of Sport and Health Sciences, University of Jyväskylä, Rautpohjankatu 8, 40700 Jyväskylä, Finland

\section{Introduction}

Frailty syndrome is characterized by diminished strength, endurance and reduced physiological functions, and can lead to vulnerability, disability, falls, long-term care and mortality $[1,2]$. Frailty occurs more commonly in women. Its prevalence increases with age, varying between 4 and 59\% depending on the definition and the population studied [3]. A consensus of opinion on how to screen, define and assess frailty has not been reached [4]. Various methods can be used to screen and identify persons with signs of frailty, for example Fried's frailty phenotype [5], the Frailty Index [6] and the FRAIL questionnaire [7]. Fried's frailty phenotype criteria [5] are often used to assess physical frailty, and there are five items: (1) unintentional weight loss, (2) low physical activity, (3) exhaustion, (4) weak grip strength and (5) slow 
walking speed. If a person meets one or two criteria, he/she is considered as pre-frail, and if a person meets three or more criteria he/she is considered as frail [5].

One characteristic of frailty is a low physical activity level [5]. Increasing physical activity among frail persons improves physical functioning (e.g. strength, mobility, balance, and flexibility) [8]. Short-term multicomponent exercise programs have improved physical functioning [9], frailty status [9], and quality-of-life [10] in frail persons. A longer duration of training (more than 5 months) seems to have greater effects on health than shorter ones in frail older adults [11]. Older adults feel that it is safer to exercise when training is supervised [12], and under supervision the intensity can be higher [13]. Further benefits of physical training in frail persons may result from individualized programs, which seem to have greater effects on mobility and physical functioning than group exercises [14]. However, there is a scarcity of exercise trials that have involved the use of validated definitions of frailty. In particular, there is a lack of long-term supervised physical exercise trials. Along with our study, the ongoing SPRINTT trial [15] is targeted on physically frail and sarcopenic older people, with the aim of filling this gap.

Our randomized controlled study HIPFRA is a real-life long-term supervised physical exercise study, targeted on home-dwelling, well-defined pre-frail and frail older adults and designed to assess the effects of physical exercise training on the duration of residing at home, and on functioning and health-related quality-of-life. The aim of this report is to describe baseline characteristics and associations between the severity of frailty vs. functional independence and quality-of-life in a randomized controlled trial involving longterm supervised home-based physical exercise.

\section{Methods}

\section{Design}

Our frailty group is part of the HIPFRA study [16], which is a randomized controlled trial carried out to investigate the effects of 12-month supervised physical exercise intervention on the days lived at home in a 24-month period (the primary outcome). Secondary outcomes are physical functioning, health-related quality-of-life (HRQoL), severity of frailty, and use of social and health-care services. The intervention group participates in supervised home-based physical exercise (60-min sessions twice a week) for 12 months, and the usual care group continues to live as usual. The hypothesis is that physical exercise intervention postpones institutionalization and increases the time living at home by 6 months. The trial received approval from the Coordinating Ethics Committee of Helsinki University Hospital, Finland and is registered at ClinicalTrials.gov (NCT02305433). Participation was voluntary and persons interested received comprehensive oral and written information about the study. For a more detailed description see [16].

\section{Participants and randomization}

Participants were recruited from the South Karelia Social and Health Care District (population 131,000), Finland, starting in December 2014. They were informed about the study by way of flyers and advertisements in local newspapers, and by health care personnel. Inclusion criteria were age $\geq 65$ years, home-dwelling (with or without home care services), able to walk independently inside with or without a mobility aid, $\geq 17$ points in the Mini-Mental State Examination (MMSE) [17] and ability to communicate in Finnish. To be eligible, the persons interested in participating needed to score at least one point in the FRAIL questionnaire [7], and fulfil at least one of the five frailty phenotype criteria [5] (Table 1).

Exclusion criteria were residing permanently in institutional care, and severe or advanced diseases, that prevented participation in physical exercise, such as severe neurological or cardiovascular disease with severely impaired physical capacities (NYHA class III or IV), severe or acute mental problems, alcohol or drug abuse, severe problems with hearing or eyesight or terminal illnesses.

The participants were first screened with using the FRAIL questionnaire [7]. This questionnaire contains five items fatigue (How often during the past 4 weeks did you feel tired?), resistance (By yourself and not using aids do you have difficulty walking up 10 steps without resting?), ambulation (By yourself and not using aids, do you have any difficulty walking $300 \mathrm{~m}$ ?), physician-diagnosed illnesses (a list of 11 illnesses), and loss of weight (more than 5\% from the previous year's weight). If the person scored one or more points, he/she continued to the next phase of recruitment.

The study nurse checked the person's eligibility to take part in the study, and verified frailty status and severity using Fried's frailty phenotype criteria (with slight modifications) [5] (Table 1). Eligible persons signed an informed consent document and the baseline assessments were performed at the participant's home. After baseline assessments, the participants were randomized to two groups: physiotherapistsupervised home-based physical exercise training $(n=150)$, and usual care $(n=150)$. Randomization was performed using a computer-generated random allocation sequence with varying block sizes.

\section{Assessments}

A more detailed description of the assessments can be found elsewhere [16]. The primary outcome measure, time 
Table 1 Frequency of frailty criteria and their distribution in the physical exercise and usual care. The $p$ values refer to a difference between the randomization groups

\begin{tabular}{|c|c|c|c|c|}
\hline \multirow[t]{2}{*}{ Frailty phenotype criteria ${ }^{a}$} & \multicolumn{3}{|c|}{ Participants meeting the criteria, n (\%) } & \multirow[t]{2}{*}{$p$ value } \\
\hline & All $(n=299)$ & $\begin{array}{l}\text { Physical } \\
\text { exercise } \\
(n=150)\end{array}$ & $\begin{array}{l}\text { Usual } \\
\text { care } \\
(n=149)\end{array}$ & \\
\hline \multicolumn{5}{|l|}{ Unintentional weight loss } \\
\hline more than 5\% (vs. weight 12 months ago) & $53(18)$ & $26(17)$ & $27(18)$ & 0.86 \\
\hline \multicolumn{5}{|l|}{ Low physical activity ${ }^{b}$} \\
\hline Under 30 min per week & $160(54)$ & $77(51)$ & $83(66)$ & 0.45 \\
\hline \multicolumn{5}{|l|}{ Exhaustion } \\
\hline $\begin{array}{l}\text { Answering "moderate amount" or "most of the } \\
\text { time" to one or both questions: How often did you } \\
\text { feel that }\end{array}$ & $186(62)$ & $90(60)$ & $96(64)$ & 0.43 \\
\hline a) everything you did was an effort? & $141(47)$ & $64(43)$ & $77(52)$ & \\
\hline b) you could not get going? & $122(41)$ & $59(39)$ & $63(42)$ & \\
\hline \multicolumn{5}{|l|}{ Weakness } \\
\hline Weak grip strength under cutoff value ${ }^{c}$ & $179(60)$ & $94(63)$ & $85(57)$ & 0.32 \\
\hline \multicolumn{5}{|l|}{ Slowness } \\
\hline Gait speed ${ }^{\mathrm{d}}<0.46 \mathrm{~m} / \mathrm{s}$ & $81(27)$ & $48(32)$ & $33(22)$ & 0.051 \\
\hline \multicolumn{5}{|l|}{${ }^{\text {a }}$ Slightly modified } \\
\hline \multicolumn{5}{|c|}{$\begin{array}{l}\text { bMinutes per week were used instead of kcal per week. Our question was "How often did you exercise dur- } \\
\text { ing the previous } 3 \text { months?" }\end{array}$} \\
\hline \multicolumn{5}{|c|}{$\begin{array}{l}{ }^{\mathrm{c}} \text { Cutoff values (stratified by BMI and gender): for women with BMI } \leq 26.0 \mathrm{~kg} / \mathrm{m}^{2} \text {, cutoff } \leq 17 \mathrm{~kg} \text {; BMI } \\
26.1-29.0 \mathrm{~kg} / \mathrm{m}^{2} \text {, cutoff } \leq 18 \mathrm{~kg} ; \text { BMI }>29.0 \mathrm{~kg} / \mathrm{m}^{2} \text {, cutoff } \leq 21 \mathrm{~kg} \text {. For men with BMI } \leq 24.0 \mathrm{~kg} / \mathrm{m}^{2} \text {, cut- } \\
\text { off } \leq 29 \mathrm{~kg} ; \mathrm{BMI} 24.1-28.0 \mathrm{~kg} / \mathrm{m}^{2} \text {, cutoff } \leq 30 \mathrm{~kg} ; \text { BMI }>28.0 \mathrm{~kg} / \mathrm{m}^{2} \text { cutoff } \leq 32 \mathrm{~kg}\end{array}$} \\
\hline
\end{tabular}

residing at home (over a period of 24 months) is assessed from the South Karelia Social and Health Care District's patient records and registers. In-patient care, hospital days, and institutionalized care (nursing home, sheltered housing) are considered as days not lived at home.

Secondary outcome measures: assessments are performed at the participant's home at baseline, and after 3, 6 and 12 months by the study physiotherapist or the study nurse, both trained to perform them. Each assessment visit takes about $1.5 \mathrm{~h}$ and consists of a structured interview, questionnaires and measurements.

Physical functioning was assessed using the Short Physical Performance Battery (SPPB) [18], the Functional Independence Measure (FIM) [19], and Lawton's instrumental activities of daily living (IADL) [20], and grip strength was measured with a Saehan dynamometer (model Sh5001, South Korea). Cognition was assessed using the MMSE [17], depressive symptoms with the Geriatric Depression Scale (GDS-15) [21], and nutritional status using the Mini Nutritional Assessment (MNA) [22]. IADL, FIM, GDS-15 and MNA data were assessed by interviewing the participant. To assess HRQoL, the participant answered the 15D questionnaire [23]. Weight (Omron HN289 equipment, Japan) and height (KaWe Person-Check equipment, Germany) were measured, and body mass index (BMI) was calculated. Regularly used medications and diseases diagnosed by a physician were asked about. Information was completed from electronic medical records, and the Charlson comorbidity index (CCI) [24] was calculated.

Demographic factors such as age, marital status, education and former occupation, form of living, and use of home and home health-care services were inquired about in the baseline interview. Perceived health, mobility ability and physical fitness were asked about using questions from the Finnish Elderly Health survey [25]. Lifestyle habits were investigated: physical activity as weekly frequency of activity sessions lasting for more than $30 \mathrm{~min}$, and smoking habits as the daily amounts of cigarettes and other products. Perceived pain was assessed by inquiring "Are you experiencing any pain at the moment or during the day?', The number of falls was investigated by asking "Have you fallen during the previous three months and if you did, did you have any associated injuries?".

\section{Statistical analyses}

Statistical comparisons between the randomization groups were made using $t$ test and the $\chi^{2}$ test, as appropriate. Statistical significances for the unadjusted hypothesis of linearity across categories of frailty severity of the study participants were evaluated using analysis of variance (ANOVA) with an appropriate contrast (orthogonal polynomial). The bootstrap 
method was used when the theoretical distribution of the test statistics was unknown or in cases of violation of the assumptions (e.g. non-normality). The normality of the variables was tested using the Shapiro-Wilk $W$ test. The Stata 15.0, StataCorp LP (College Station, TX, USA) statistical package and IBM SPSS statistics 25.0 were used for the analyses. In the analyses, two frailty categories (scores four and five) were combined to achieve an appropriate amount of persons. The level of statistical significance was set at 0.05 in all the analyses. For statistical power calculation, see Soukkio et al. [16].

\section{Results}

\section{Recruitment and baseline characteristics}

Five-hundred and twenty persons were screened using the FRAIL questionnaire. Of these, $43 \%$ were screened by the health-care personnel and $57 \%$ by the study personnel. Of the screened persons, 224 women and 76 men met all the inclusion criteria and were willing to participate (Fig. 1). One person withdrew their informed consent after randomization and denied use of the data, decreasing the number of participants in the usual care group to 149 . The mean age was 82.5 years (range 65-98). According to the frailty criteria, 182 participants were pre-frail ( 1 or 2 criteria of the 5 fulfilled), and 117 were frail (3-5 criteria fulfilled) at baseline. Nine participants fulfilled all five frailty criteria (Table 1). The mean SPPB score was 6.2 (SD 2.6), and the mean FIM total score was 108.8 (10.6). Of the participants, $239(80 \%)$ used a rollator walker or stick. One hundred and seventy-four (58\%) lived alone, and $25 \%$ received home care or home health-care services organized through the hospital district. The groups were similar in their baseline characteristics (Table 2).

\section{Severity of frailty, and functional independence}

The severity of frailty was inversely and linearly associated with FIM scores (Fig. 2). With an increase in the number of frailty criteria met, FIM scores decreased. In the pre-frail participants, the mean FIM score was 113 (SD 8) and in the frail persons it was $103(11)$ ( $p$ for linearity <0.001). The same pattern was seen in both FIM subcomponents; in the motor component, the mean score in the pre-frail persons was 81 (SD 6) and in the frail persons 74 (9) ( $p$ for linearity $<0.001)$, and in the cognition component the mean scores were 32 (4) and $30(4)(p<0.001)$, respectively.

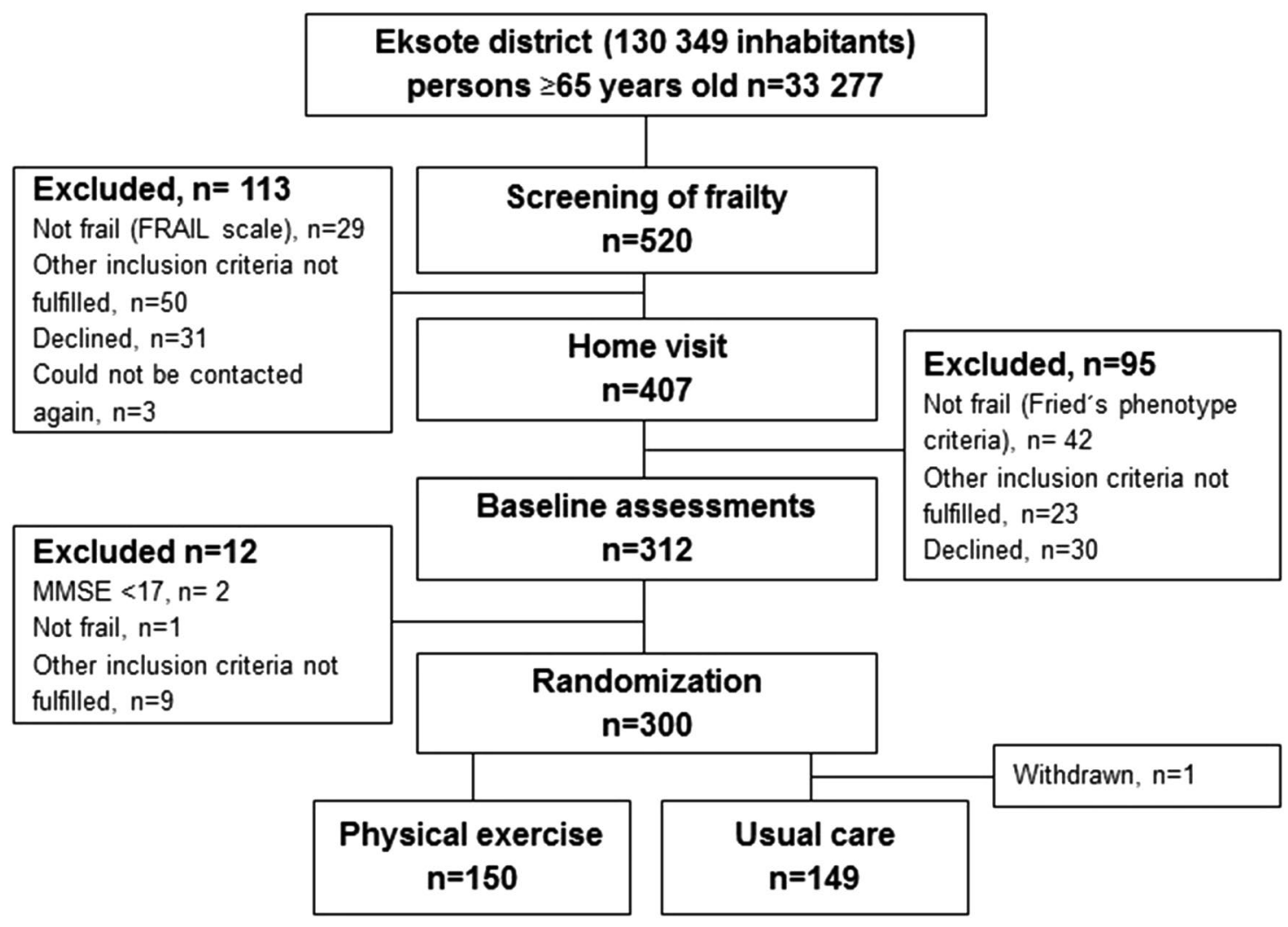

Fig. 1 Flowchart of the study 
Table 2 Baseline characteristics of all participants and in the randomized groups (physical exercise and usual care)

\begin{tabular}{|c|c|c|c|c|}
\hline Characteristics & All $(n=299)$ & $\begin{array}{l}\text { Physical exercise } \\
(n=150)\end{array}$ & Usual care $(n=149)$ & $p$ value \\
\hline Women, $n(\%)$ & $224(75)$ & $114(76)$ & $110(74)$ & 0.67 \\
\hline Age, mean (SD) & $82.5(6.3)$ & $82.2(6.3)$ & $82.7(6.3)$ & 0.44 \\
\hline $\mathrm{BMI}^{\mathrm{a}}\left(\mathrm{kg} / \mathrm{m}^{2}\right)$, mean $(\mathrm{SD})$ & $28.5(5.9)$ & $28.4(5.5)$ & $28.6(6.1)$ & 0.78 \\
\hline Marital status, $n(\%)$ & & & & 0.19 \\
\hline Married/in a relationship & $118(39)$ & $56(37)$ & $62(42)$ & \\
\hline Single/divorced & $46(15)$ & $19(13)$ & $27(18)$ & \\
\hline Widowed & $135(45)$ & $75(50)$ & $60(40)$ & \\
\hline Education $<9$ years, $n(\%)$ & $195(63)$ & $99(66)$ & $90(60)$ & 0.32 \\
\hline $\mathrm{MMSE}^{\mathrm{b}}$, mean $(\mathrm{SD})$ & $24.4(3.1)$ & $24.2(3.1)$ & $24.6(3.2)$ & 0.39 \\
\hline Severity of frailty ${ }^{c}$ & & & & 0.94 \\
\hline Pre-frail, $1-2$ of the 5 criteria, $n(\%)$ & $182(61)$ & $91(61)$ & $91(61)$ & \\
\hline Frail, $3-5$ of the 5 criteria, $n(\%)$ & $117(39)$ & $59(39)$ & $58(39)$ & \\
\hline \multicolumn{5}{|l|}{ Physician-diagnosed diseases or disorders, $n(\%)$} \\
\hline Coronary heart disease & $128(43)$ & $57(38)$ & $71(48)$ & 0.09 \\
\hline Stroke or TIA ${ }^{\mathrm{d}}$ & $70(23)$ & $37(25)$ & $33(22)$ & 0.61 \\
\hline Hypertension & $220(74)$ & $110(73)$ & $110(74)$ & 0.92 \\
\hline Musculoskeletal diseases $^{\mathrm{e}}$ & $253(85)$ & $129(86)$ & $124(83)$ & 0.51 \\
\hline Respiratory diseases $\left(\mathrm{COPD}^{\mathrm{f}}\right.$, asthma) & $36(12)$ & $16(11)$ & $20(13)$ & 0.46 \\
\hline Depressive symptoms & $50(17)$ & $25(17)$ & $25(17)$ & 0.98 \\
\hline Alzheimer's disease or other dementias & $41(14)$ & $19(13)$ & $22(15)$ & 0.60 \\
\hline $\mathrm{CCI}^{\mathrm{g}}$, mean $(\mathrm{SD})$ & $2.0(1.7)$ & $2.0(1.7)$ & $2.0(1.7)$ & 0.84 \\
\hline Number of regular medications, mean (SD) & $6.8(3.1)$ & $6.7(3.2)$ & $7.0(3.1)$ & 0.43 \\
\hline Walking aids, $n(\%)$ & $239(80)$ & $122(81)$ & $117(79)$ & 0.54 \\
\hline Walking sessions (> $30 \mathrm{~min}$ ) weekly, $n(\%)$ & & & & 0.11 \\
\hline 4-7 times & $37(12)$ & $15(10)$ & $22(15)$ & \\
\hline $1-3$ times & $79(26)$ & $47(31)$ & $32(21)$ & \\
\hline$<1$ time & $183(61)$ & $88(59)$ & $95(64)$ & \\
\hline \multicolumn{5}{|l|}{ Grip strength $^{\mathrm{h}}(\mathrm{kg})$, mean $(\mathrm{SD})$} \\
\hline Women & $16.5(5.5)$ & $16.3(5.7)$ & $16.7(5.3)$ & 0.53 \\
\hline Men & $27.7(7.6)$ & $27.3(7.6)$ & $28.2(7.7)$ & 0.61 \\
\hline $\mathrm{SPPB}^{\mathrm{i}}$, mean $(\mathrm{SD})$ & $6.2(2.6)$ & $6.1(2.7)$ & $6.3(2.5)$ & 0.49 \\
\hline \multicolumn{5}{|l|}{ FIM $^{\mathrm{j}}$, mean $(\mathrm{SD})$} \\
\hline Total & $108.8(10.6)$ & $108.8(10.3)$ & $108.8(10.9)$ & 0.97 \\
\hline Motor & $78.0(7.8)$ & $78.0(7.6)$ & $78.0(8.0)$ & 0.92 \\
\hline Cognition & $30.9(4.0)$ & $30.9(4.0)$ & $31.0(3.9)$ & 0.85 \\
\hline HRQoL $15 D^{\mathrm{k}}$, mean (SD) & $0.712(0.091)$ & $0.719(0.084)$ & $0.705(0.097)$ & 0.19 \\
\hline GDS- $15^{1}$, mean (SD) & $4.8(2.7)$ & $4.7(2.5)$ & $4.9(2.8)$ & 0.64 \\
\hline $\mathrm{MNA}^{\mathrm{m}}$, mean $(\mathrm{SD})$ & $23.1(3.2)$ & $23.3(3.1)$ & $22.7(3.4)$ & 0.15 \\
\hline Falls during the previous 3 months, $n(\%)$ & & & & 0.89 \\
\hline None & $192(64)$ & $98(65)$ & $94(64)$ & \\
\hline $1-2$ & $80(27)$ & $40(27)$ & $40(27)$ & \\
\hline$\geq 3$ & $26(9)$ & $12(8)$ & $14(9)$ & \\
\hline Perceived pain ${ }^{\mathrm{n}}, n(\%)$ & $217(73)$ & $103(69)$ & $114(77)$ & 0.07 \\
\hline
\end{tabular}

Frequencies (\%) or means (SD) are shown. Values of $p$ refer to differences between the randomization groups

${ }^{a}$ BMI, Body Mass Index

${ }^{\mathrm{b}}$ MMSE, Mini-Mental State Examination [17]

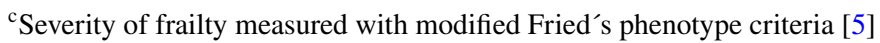

${ }^{\mathrm{d}}$ TIA, Transient Ischaemic Attack

${ }^{\mathrm{e}}$ Musculoskeletal diseases, at least one of the following: arthritis, osteoporosis, rheumatoid arthritis, and low back pain 
Table 2 (continued)

${ }^{\mathrm{f}}$ COPD, Chronic Obstructive Lung Disease

${ }^{\mathrm{g}} \mathrm{CCI}$, Charlson Comorbidity Index [24]

${ }^{\mathrm{h}}$ Mean of the best values (of three tries) from both hands

${ }^{\text {i }}$ SPPB, Short Physical Performance Battery [18]

${ }^{\mathrm{j}} \mathrm{FIM}$, Functional Independence Measure [19]

${ }^{\mathrm{k}}$ Health-related quality-of-life questionnaire (15D) [23]

${ }^{\mathrm{l}}$ GDS-15, Geriatric Depression Scale-15 [21]

${ }^{m}$ MNA, Mini Nutritional Assessment [22]

${ }^{\mathrm{n}}$ Answering "yes" to the question, "Are you experiencing any pain at the moment or during the day?"

Fig. 2 FIM (Functional Independence Measure) scores (total, cognition and motor) by categories of frailty severity (frailty scores 1, 2, 3, and 4-5) at baseline. Mean $(95 \% \mathrm{CI})$. The total number of participants was 299, of whom 91 persons were in category 1,91 in category 2,82 in category 3 , and 35 in category $4-5$. Values of $p$ are for linearity across frailty categories

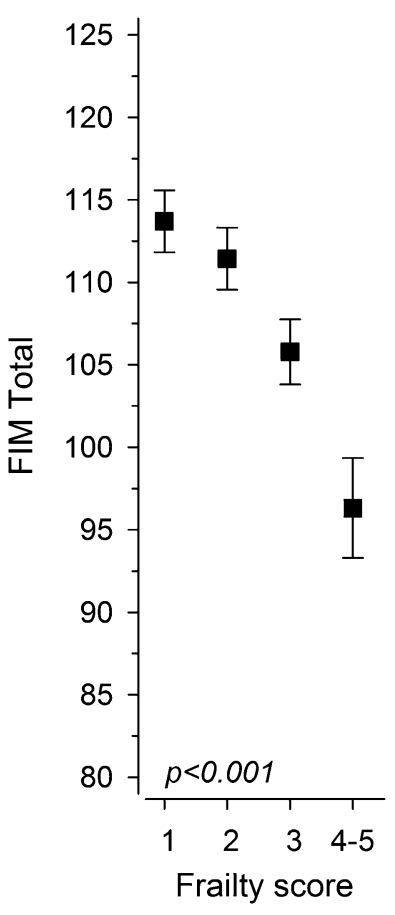

\section{Severity of frailty, and health-related quality-of-life}

An inverse association between severity of frailty and HRQoL was also seen (Fig. 3). Those who were frail (scores $3-5$ ) had lower scores in the 15D questionnaire, indicating worse quality-of-life compared with persons with pre-frailty ( $p$ for linearity $<0.001)$.

\section{Discussion}

We recruited 300 persons with signs of frailty and randomized them to physical exercise and usual care groups. We were able to recruit both pre-frail and frail persons. The participants' physical functioning at baseline according to SPPB scores was impaired while most of them did not have major problems in functional independence. The severity of
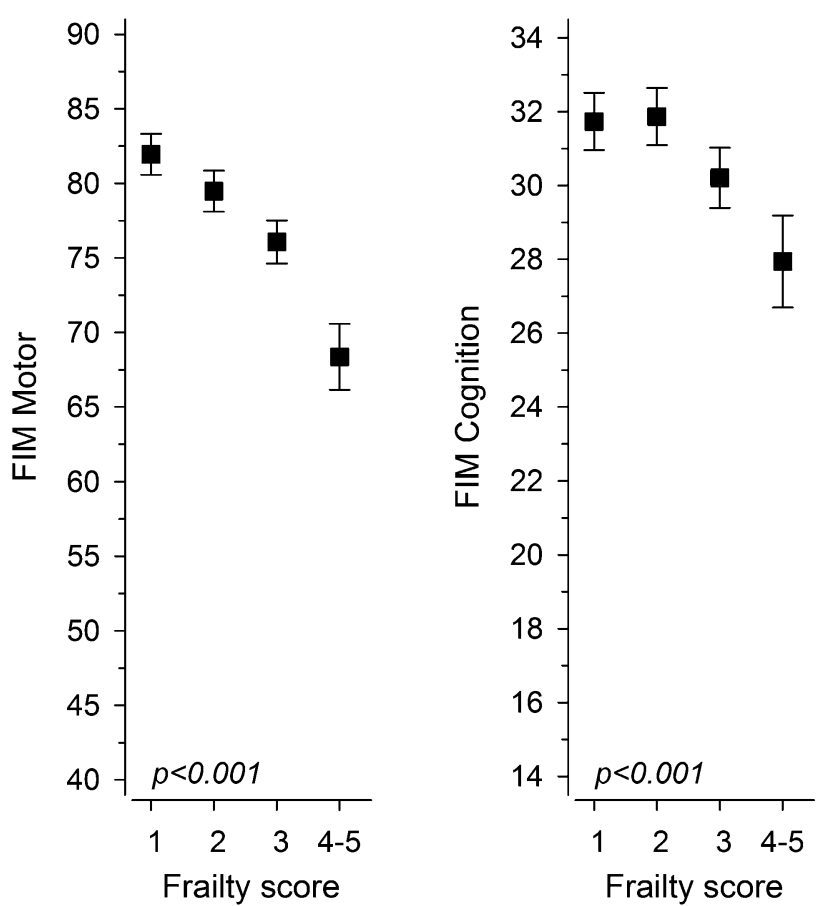

frailty was linearly associated with both physical functioning and HRQoL.

Slightly modified phenotype criteria were used to detect older persons with signs of frailty. During the recruitment process, we were able to recruit a high number of physically frail older adults from the area of South Karelia. Recruitment had two main sources; advertisements and health-care personnel. The personnel's information about eligible candidates was important for us to find those more severely physically frail persons. On the other hand, persons who contacted us directly were usually in better condition.

According to the frailty characteristics, our participants were markedly physically frail. A majority of participants were pre-frail (61\%) with low SPPB scores, which gives us an opportunity to observe changes in frailty status during the intervention year. In our trial, the two most prevalent frailty criteria were weakness (60\%) and exhaustion (62\%). Findings from two large population-based studies [26] revealed 


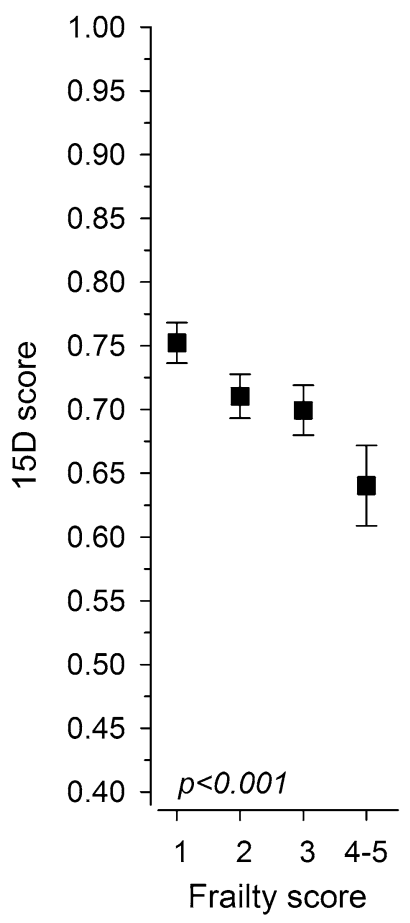

Fig. 3 Health-related quality-of-life (15D) scores by categories of frailty severity (frailty scores 1, 2, 3, and 4-5) at baseline. Mean (95\% CI). The total number of participants was 299 , of whom 91 persons were in category 1,91 in category 2,82 in category 3 , and 35 in category 4-5. Values of $p$ are for linearity across frailty categories

that weakness was the first frailty criterion, occurring as early as 9 years prior to the onset of frailty, while low physical activity and slowness occurred 6 years prior to onset. The last frailty criterion occurring at or before the onset of frailty was weight loss [26]. Among our participants, the occurrence of weight loss was only $18 \%$, being in line with the results of other studies [5, 27].

The participants' mean age was high, they suffered from multiple diseases and often reported polypharmacy, most of them lived alone and a very high proportion (80\%) used mobility devices. Even though the majority of our participants were pre-frail, their mean SPPB scores were relatively low compared with those reported in the LIFE [28], and SPRINTT [29] studies, and by Tarazona-Santabalbina et al. [9], reflecting our participants' prevailing physical frailty, which can be considered as a strength of this study. On the other hand, the SPRINTT [29] and LIFE [30] studies did not involve participants needing mobility devices, and frailty phenotype as an inclusion criterion was not used.

The mean FIM score of 109 among our participants indicates fairly independent functioning compared for example, with that in Finnish Alzheimer exercise trial, where the mean FIM score was 87 [31]. A declining FIM score reflects more dependence on help from others in everyday chores. In our study, an inverse association between the severity of frailty and functional independence was observed. A negative association has been found between Edmonton Frailty Scale (EFS) and FIM scores in patients at discharge from a short-term geriatric ward [32]. To our knowledge, the association between frailty and FIM scores has not been studied before in community-living older adults. It seems that the severity of frailty also shows an inverse association with HRQoL and our findings are in line with those in previous studies [33, 34].

A strength of our study is that it is a rigorously performed randomized controlled trial, in real life. The participants are truly physically frail or pre-frail thus indicating neither ceiling nor floor effects on our outcomes. Another strength is that we used validated measurements and questionnaires. The research physiotherapist and the nurse were trained to perform the assessments and are monitored. Assessments and the intervention are performed in the participants' homes, so they need no transportation. As a weakness, the study assessors cannot be blinded since they participated in scheduling the trial although they do not administer the exercise intervention. Furthermore, our primary aim of increasing the duration of home living by 6 months is relatively large. However, this frail population is at high risk of use of hospital and other institutional care. The risk of contamination of the groups is relatively low since the participants' baseline physical activity is very low and the supply of physiotherapy for this patient group is limited in public health care.

\section{Conclusions}

Recruitment of the participants was successful. At baseline the characteristics of the two groups were similar. The participants were physically frail or pre-frail according to modified Fried's phenotype criteria. The occurrence of the five frailty phenotype criteria were in line with the findings of other studies. An increase in the number of frailty phenotype criteria seems to be associated with a decline in functional independence and in health-related quality-of-life.

Funding The HIPFRA study is funded by the South Karelia Social and Health Care District (Eksote, register number 1236/00.01.05.01/2013), by two governmental funding sources; The Social Insurance Institution of Finland (SII, register number 94/331/2013) and State Research Funding for Academic Health Research (Ministry of Social Affairs and Health), and by the Vyborg Foundation Against Tuberculosis. The funding bodies had no role in the design of the study, in collection, analysis and interpretation of the data, or in writing the manuscript.

\section{Compliance with ethical standards}

Conflicts of interest The authors declare that they have no conflicts of interest. 
Ethics approval All the procedures performed in studies involving human participants were in accordance with the ethical standards of the institutional and/or national research committee and with the 1964 Helsinki Declaration and its later amendments or comparable ethical standards.

Informed consent A written informed consent was obtained from all individual participants included in the study.

\section{References}

1. Morley JE, Vellas B, Abellan van Kan G et al (2013) Frailty consensus: a call to action. J Am Med Dir Assoc 14:392-397

2. Clegg A, Young J, Illiffe S, Rikkert MO, Rockwood K (2013) Frailty in elderly people. Lancet $381: 752-762$

3. Collard RM, Boter H, Schoevers RA, Oude Voshaar RC (2012) Prevalence of frailty in community-dwelling older persons: a systematic review. J Am Geriatr Soc 60:1487-1492

4. Bouillon K, Kivimaki M, Hamer M et al (2013) Measures of frailty in population-based studies: an overview. BMC Geriatrics 13:64

5. Fried LP, Tangen CM, Walston J et al (2001) Cardiovascular health study collaborative research group. Frailty in older adults: evidence for a phenotype. J Gerontol A Biol Sci Med Sci 56:146-156

6. Rockwood K, Mitnitski A (2007) Frailty in relation to the accumulation of deficits. J Gerontol. 62A:722-727

7. Morley JE, Malmstrom TK, Miller DK (2012) A simple frailty questionnaire (FRAIL) predicts outcomes in middle aged African Americans. J Nutr Health Aging 16:601-608

8. Dent E, Lien C, Lim WS et al (2017) The Asia-Pacific clinical practice guidelines for the management of frailty. J Am Med Dir Assoc 18:564-575

9. Tarazona-Santabalbina FJ, Gómez-Cabrera MC, Pérez-Ros P et al (2016) A Multicomponent exercise intervention that reverse frailty and improves cognition, emotion and social networking in the community-dwelling frail elderly: a randomized clinical trial. J Am Med Dir Assoc 17:426-433

10. Langlois F, Vu TTM, Chassé K, Dupuis G, Kergoat M-J, Bherer L (2013) Benefits of physical exercise training on cognition and quality of life in frail older adults. J Gerontol B Psychol Sci Soc Sci 68:400-404

11. Theou O, Stathokostas L, Roland KP et al (2011) The effective interventions for the management of frailty: A systematic review. J Aging Res. https://doi.org/10.4061/2011/569194

12. Franco MR, Howard K, Sherrington C et al (2015) Eliciting older people's preferences for exercise programs: a best-worst scaling choice experiment. J Physiother 61:34-41

13. Bray NW, Smart RR, Jakobi JM, Jones GR (2016) Exercise prescription to reverse frailty. Appl Physiol Nutr Metab 41:1112-1116

14. de Vries NM, van Ravensberg CD, Hobbelen JSM, Olde Rikkert MGM, Staal JB, Nijhuis-Van der Sanden MWG (2012) Effects of physical exercise therapy on mobility, physical functioning, physical activity and quality of life in community-living older adults with impaired mobility, physical disability and/or multimorbidity: a meta-analysis. Ageing Res Rev 11:136-149

15. Landi F, Cesari M, Calvani R et al (2017) The "Sarcopenia and physical fRailty IN older people: multi componenT treatment strategies" (SPRINTT) randomized controlled trial: design and methods. Aging Clin Exp Res 29:89-100

16. Soukkio P, Suikkanen S, Kääriä S et al (2018) Effects of home-based physiotherapy on duration of living at home and functional capacity among older persons with signs of frailty or with recent hip fracture-protocol of a randomized controlled trial (HIPFRA study). BMC Geriatrics 18:232

17. Folstein MF, Folstein SE, McHug PR (1975) "Mini-mental state". A practical method for grading the cognitive state of patients for the clinician. J Psychiatr Res 12:189-198

18. Guralnik J, Simonsick E, Ferrucci L et al (1994) A short physical performance battery assessing lower extremity function: association with self-reported disability and prediction of mortality and nursing home admission. J Gerontol 49:85-94

19. Granger CV, Hamilton BB, Zielezny M, Sherwin FS (1986) Advances in functional assessment in medical rehabilitation. Top Geriatr Rehabil 1:59-74

20. Lawton MP, Brody EM (1969) Assessment of older people: self-maintaining and instrumental activities of daily living. Gerontologist 9:179-186

21. Sheikh JI, Yesavage JA (1986) Geriatric Depression Scale (GDS): Recent evidence and development of a shorter version. In: Brink TL (ed) Clinical gerontology: a guide to assessment and intervention. The Haworth Press, New York, pp 165-173

22. Vellas B, Villars H, Abellan G et al (2006) Overview of the MNA ${ }^{\circledR}$ - its history and challenges. J Nutr Health Aging. 10:456-465

23. Sintonen H (1994) The 15D-measure of health-related quality of life. I. Reliability, validity and sensitivity of its health state descriptive system. National centre for health program evaluation, working paper 41, Melbourne, Australia https://pdfs.seman ticscholar.org/64d2/f291b61e8f7ca83cf890736cf52d2ead0a7 1.pdf Accessed Feb 21, 2019

24. Charlson ME, Pompei P, Ales KL, MacKenzie CR (1987) A new method of classifying prognostic comorbidity in longitudinal studies: development and validation. J Chron Dis 40:373-383

25. Helldán A, Helakorpi S (2014) Health behaviour and health among the Finnish elderly, Spring 2013, with trends 1993-2013. National institute for health and welfare (THL), Report 15/2014. https://urn.fi/URN:ISBN:978-952-302-188-4. Accessed Feb 21 2019

26. Stenholm S, Ferrucci L, Vahtera J et al (2018) Natural course of frailty components in people who develop frailty syndrome: evidence from two cohort studies. J Gerontol. https://doi. org/10.1093/gerona/gly 132

27. Op het Veld LPM, van Rossum E, Kempen GIJM, de Vet HCW, Hajema KJ, Beurskens AJHM, (2015) Fried phenotype of frailty: cross-sectional comparison of three frailty stages on various health domains. BMC Geriatrics 15:77

28. Pahor M, Guralnik J, Ambrosius WT et al (2018) Effect of structured physical activity on prevention of major mobility disability in older adults: the LIFE study randomized clinical trial. JAMA 18:2387-2396

29. Marzetti E, Cesari M, Calvani R et al (2018) The "Sarrcopenia and Physical fRailty IN older people: multi-componenT treatment strategies" (SPRINTT) randomized controlled trial: case finding, screening and characteristics of eligible participants. Exp Gerontol 113:48-57

30. Fielding RA, Rejeski WJ, Blair S et al (2011) The lifestyle interventions and independence for elders study: design and methods. J Gerontol A Biol Sci Med Sci 66A:1226-1237

31. Pitkälä KH, Pöysti MM, Laakkonen M-L et al (2013) Effects of the finnish alzheimer disease exercise trial (FINALEX) -a randomized controlled trial. JAMA Intern Med 173:894-901

32. Kawaryshanker S, Raymond W, Ingram K, Inderjeeth CA (2014) Effect of frailty on functional gain resource utilisation, and discharge destination: an observational prospective study in a GEM ward. Curr Gerontol Geriatr Res. https://doi. org/10.1155/2014/357857 
33. Masel MC, Graham JE, Reistetter TA, Markides KS, Ottenbacher KJ (2009) Frailty and health related quality of life in older Mexican Americans. Health Qual Life Outcomes 7:70. https://doi. org/10.1186/1477-7525-7-70

34. Kojima G, Iliffe S, Morries RW et al (2016) Frailty predicts trajectories of quality of life over time among British community dwelling older people. Qual Life Res. https://doi.org/10.1007/ s11136-015-1213-2
Publisher's Note Springer Nature remains neutral with regard to jurisdictional claims in published maps and institutional affiliations. 